\title{
PREVALENCE OF HELICOBACTER PYLORI DISEASE IN PATIENTS WITH DYSPEPSIA ON UPPER GI ENDOSCOPY
}

Kasinath Panda1, P. Naresh Kumar ${ }^{2}$

${ }^{1}$ Assistant Professor, Department of General Surgery, Sri Venkateshwaraa Medical College Hospital and Research Center, Pondicherry. 2 Professor and HOD, Department of General Surgery, Sri Venkateshwaraa Medical College Hospital and Research Center, Pondicherry.

ABSTRACT

\section{BACKGROUND}

Helicobacter pylori is known to be a highly prevalent infection among persons in developing countries. It is firmly established as the aetiologic agent for acute and chronic gastritis and a predisposing factor in peptic ulcer disease, gastric carcinoma and B-cell mucosaassociated lymphoid tissue (MALT) lymphoma. Dyspepsia is a common gastrointestinal disorder and the most common indication for gastroscopy.

Objective- To determine the prevalence of H. pylori infection among patients with dyspepsia referred for upper gastrointestinal endoscopy at SVMCH \& RC, Pondicherry.

\section{MATERIALS AND METHODS}

Patients with dyspepsia underwent gastroscopy, and biopsies were taken from the antral portions of their stomach and processed. Their serum samples were tested for H. pylori infection using ELISA to detect antibodies.

\section{RESULTS}

In our study, there were 100 study subjects. Out of 100 patients, there were 62 male patients and 38 female patients, age ranging from 19 to 60 years (mean $=44.59$ ). Out of 100 patients, 56 were diagnosed to be having Helicobacter pylori (56\%). In the study, highest number of patients were in the age group of 51-60 years (23\%).

\section{CONCLUSION}

In this study, we found that Helicobacter pylori was consistently associated with peptic ulcer disease. Hence, we recommend the eradication of bacteria in patients, positive for the bacterium, who have peptic ulcer disease and dyspepsia.

\section{KEYWORDS}

Dyspepsia, Acid-Peptic Disease, Helicobacter Pylori, Urease, Giemsa, Peptic Ulcer, Non-ulcer Dyspepsia.

HOW TO CITE THIS ARTICLE: Panda K, Kumar PN. Prevalence of Helicobacter pylori disease in patients with dyspepsia on upper GI endoscopy. J. Evolution Med. Dent. Sci. 2017;6(72):5132-5136, DOI: 10.14260/jemds/2017/1115

\section{BACKGROUND}

Dyspepsia is a common symptom in surgical practice. The prevalence of dyspepsia is high, consuming considerable medical and economic resources. Dyspepsia is a combination of symptoms, often related to food and that includes nausea, bloating sensation, epigastric burning sensation, epigastric pain or discomfort, indigestion, heartburn. Upper GI endoscopy is gold standard for diagnosis of structural disease in a patient with dyspepsia and is the investigation of choice for dyspepsia particularly where Radiology has been negative. Advantage of endoscopy is used for biopsy and identifying $\mathrm{H}$. pylori infection.

\section{Objectives}

1. To study the prevalence of Helicobacter pylori in patients with dyspepsia, undergoing upper gastrointestinal endoscopy.

2. To assess the risk factors for dyspepsia.

3. To assess the symptoms for dyspepsia.

Financial or Other, Competing Interest: None.

Submission 23-06-2017, Peer Review 24-08-2017,

Acceptance 31-08-2017, Published 07-09-2017.

Corresponding Author:

Dr. P. Naresh Kumar,

Professor and HOD,

Department of General Surgery,

Sri Venkateshwaraa Medical College Hospital and Research Center,

Pondicherry-605102.

E-mail:drnk.2011@gmail.com

DOI: $10.14260 /$ jemds $/ 2017 / 1115$

\section{(c) $(7)$}

\section{MATERIALS AND METHODS}

\section{Source of Data}

This is a descriptive study. This is a 1-1/2-year study of all cases presented with dyspepsia symptoms admitted in SVMCH\&RC, Pondicherry. All the patients with dyspepsia presenting to OPD were admitted in surgery wards during the study period and taking written informed consent was included in the study.

\section{Inclusion Criteria}

- Patients between 15 - 60 years of age.

- Patients having chronic upper abdominal pain.

- Patients showing symptoms of dyspepsia.

- Patients diagnosed having chronic gastritis, gastric/duodenal ulcers on gastroduodenoscopy.

\section{Exclusion Criteria}

- Patients who have received anti-Helicobacter pylori treatment unwilling or unfit patients for gastroscopy.

- Patients who were subjected to UGI endoscopy after investigations.

Data regarding clinical parameters, symptoms, investigations, and endoscopic diagnosis were recorded in the proforma. Biopsy specimen was submitted to histopathological examination. 


\section{Anatomy}

Stomach is the most dilated part of the alimentary tract, extending from the Cardiac end to the pyloric end. The stomach is subdivided into (Fig 1):

1. Fundus.

2. Body.

3. Pyloric antrum.

4. Pyloric canal.

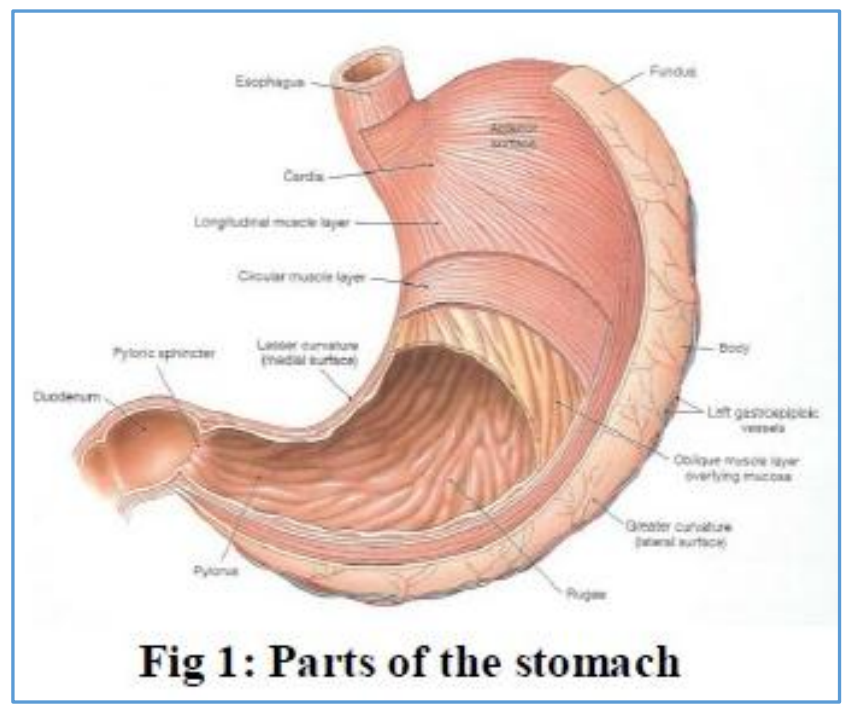

Fundus is that part which rises above the level of cardiac end of the stomach.

Body is that portion situated between the fundus and the lesser curvature of stomach.

\section{The Pyloric Part is Situated below the Body and Consists} of:

a. Pyloric antrum.

b. Pyloric canal.

It is the Pyloric antrum where Helicobacter Pylori is most Frequently Colonised. Stomach wall has four basic layers:

1. Mucous membrane.

2. Submucosa.

3. Muscular layer.

4. Serosa.

The duodenum is the most proximal fixed part of the small intestine, and joins the stomach to the jejunum. It is approximately $20-30 \mathrm{~cm}$ in length and it is arbitrarily divided into four parts corresponding to the duodenal bulb, and the descending, horizontal and ascending portions. A barium meal shows the duodenal bulb to be triangular with shallow longitudinal folds that become obliterated when the cap is distended. The second part of the duodenum descends retroperitoneally on the right of the midline at the level of the first and second lumbar vertebrae. It lies close to the head of the pancreas and the papilla of Vater (duodenal ampulla) opens on its medial wall at approximately the mid-point.

The papilla can be more easily recognised endoscopically by its relationship to the longitudinal fold. The pancreatic duct and the common bile duct enter the duodenum at the papilla. The mucosal appearance of the second part of the duodenum is quite different from the smooth lining of the duodenal bulb, for it has the circular folds characteristic of the small intestine, the valvulae conniventes. The third part of the duodenum is also retroperitoneal, crosses the midline at the level of the third lumbar vertebra and continue to the head of the pancreas. This part of the duodenum is crossed inferiorly by the superior mesenteric artery and vein. The fourth part of the duodenum ascends obliquely before turning abruptly downwards and anteriorly, where its junction with the jejunum is anchored by a fibromuscular structure, the ligament of Treitz. Lying above the fourth part of the duodenum is the body of the pancreas.

The normal histology of the duodenum comprises mucosa, muscularis mucosae, submucosa and the circular and longitudinal muscle coast. In the submucosa, unique to the duodenum are Brunner's glands. They secrete mucus and open into the crypts of Lieberkuhn at the base of the villi. The muscularis mucosae is often broken up around the glandular elements. Brunner's glands are most numerous in the first part of the duodenum, decreasing distally. The mucosa, in common with the rest of the small bowel, has tall villi between which are the crypts of Lieberkuhn that dip down to the muscularis mucosae. The surface epithelium of the villi and crypts is a mixture of absorptive cells and goblet cells. The former has prominent microvilli on their luminal border. There is a gradual maturation of cells from the crypts base to the tips of the villus. Paneth cells and cells of the APUD system are also to be found within the crypts. In general, the duodenal villi are slightly broader than those in the jejunum.

The Helicobacter pylori colonises in the mucous layer of gastric antrum and it is important in relevance to its possible aetiology of peptic ulcer disease.

\section{Physiology}

The cells of gastric glands secrete about $2500 \mathrm{~mL}$ of gastric juice daily. The juice mainly contains hydrochloric acid, pepsin, intrinsic factor, electrolytes and mucus. Hydrochloric acid is produced by parietal cells in the body of the stomach. It kills many ingested bacteria, provides the necessary $\mathrm{pH}$ for the pepsin to start protein digestion and stimulates the secretion of bile and pancreatic juice.

The gastric mucosa is protected from the acid and pepsin by mucus content of gastric juice which forms a flexible gel that coats the mucosa. The surface mucous cells also secrete bicarbonate ions which are trapped in the mucus gel, so that the $\mathrm{pH}$ gradient which is established ranges from $\mathrm{pH}$ 1-2 at the luminal side, to $\mathrm{pH}$ 6-7 at the surface of the epithelial cells. The surface membrane of the mucosal cells and tight junctions between cells are also part of the mucosal barrier, which prevents the back diffusion of $\mathrm{H}+$ ions and protects the epithelium from damage.

\section{RESULTS}

In our study of 100 patients who presented with dyspepsia, upper GI Endoscopy was done as an initial diagnostic evaluator tool. In our study, there are 100 study subjects. Out of 100 patients, there were 62 male patients and 38 female patients,

Mean Age ranged from 19 to 60 years (mean $=44.59$ ). Out of 100 patients, 56 were diagnosed to be having Helicobacter pylori (56\%). In the study, highest number of patients were in the age group of 51-60 years (23\%). In our study, most 
common risk factor for dyspepsia was Alcohol (39\%) followed by Smoking (37\%), Pan chewing (34\%). The symptoms regarding the cases got admitted are regurgitation in 16 cases, early satiety in 22 cases, anorexia in 20 cases, nausea and vomiting in 42 cases and epigastric pain in 82 cases is the most common symptom in these cases. Among all patients, 56 of them were $\mathrm{H}$. pylori positive. $53.8 \%$ of males were $\mathrm{H}$. pylori positive. $50.8 \%$ of females were H. pylori positive. Depending on the endoscopic findings, all these patients were categorised into 2 groups.

1. Ulcer dyspepsia ${ }^{1}$ - In this group, there were 29 patients out of which, 19 were male and 10 female. The age range was from 32-60 years (mean= 51.0). 20 out of these 29 Patients were Helicobacter pylori positive (68.9\%).

2. Non-ulcer dyspepsia - In this group, there were 71 patients, comprising of 45 males and 26 females. Out of 71 patients, 18 patients were infected with Helicobacter pylori (25.3\%). The age range was from 18 to 60 years (mean $=41.95$ ).

\begin{tabular}{|c|c|c|}
\hline Sex & Frequency & Percent \\
\hline Male & 62 & 62 \\
\hline Female & 38 & 38 \\
\hline \multicolumn{2}{|c|}{ Table 1. Sex Distribution } \\
\hline
\end{tabular}

\begin{tabular}{|c|c|c|}
\hline Categories & Frequency & Percent \\
\hline Regurgitation & 16 & 16 \\
\hline Early satiety & 22 & 22 \\
\hline Anorexia & 20 & 20 \\
\hline Nausea/Vomiting & 42 & 42 \\
\hline Epigastric pain & 82 & 82 \\
\hline \multicolumn{2}{|c|}{ Table 2. Distribution by Symptoms } \\
\hline
\end{tabular}

\begin{tabular}{|c|c|c|}
\hline Sex & $\begin{array}{c}\text { H. Pylori } \\
\text { Positive }\end{array}$ & $\begin{array}{c}\text { H. Pylori } \\
\text { Negative }\end{array}$ \\
\hline Male & 30 & 32 \\
\hline Female & 26 & 12 \\
\hline Table 3. Sex Distribution of H. pylori Positive Samples \\
\hline
\end{tabular}

\section{DISCUSSION}

Helicobacter pylori colonises the mucous layer of the stomach which provides the ecological niche in the antrum, which is conducive for its habitations. The breakdown of mucous layer and damage to surface epithelial cells are the basis of "Leaking Proof" hypothesis of the pathogenesis of Helicobacter pylori.

Dyspepsia $^{2}$ is a common symptom of upper GI disorder. Upper GI endoscopy is a useful diagnostic modality to identify the specific pathology in patients with? Dyspepsia. Dyspepsia is more common in male patients as compared to female. It is more common in age group of 25-50 years of age.

The term dyspepsia refers to a symptom complex that has its origin in the upper gastrointestinal tract, is localised to the upper abdomen, and is generally meal related. Functional dyspepsia is an inhomogeneous syndrome. The pain may resemble that of acid-peptic diseases and the bloat that of gastric dysmotility.

\section{Based on Symptoms}

Four subgroups of functional dyspepsia have been described.

a. Ulcer-like,

b. Gastro-oesophageal reflux-like, c. Dysmotility-like,

d. Unspecified.

\section{Aetiopathogenesis}

Delayed gastric emptying and antral hypomotility may be detected especially in those who present with bloating and early satiety. Patients with pain suggestive of acid-peptic disease may have increased sensitivity to acid; the role of gastritis or duodenitis ${ }^{3}$ and of Helicobacter Pylori infection is not clear. Many patients with this condition implicate particular articles of diet as cause of symptoms. Higher anxiety have been described in these patients, but these are not specific.

\section{Clinical Features}

Pain or discomfort in the upper abdomen with the predominant symptoms like Bloating, Early Satiety, Nausea.

\section{Investigations}

1. Investigations are mandatory in the following situations; Late age of onset of symptoms ( $>40$ years), weight loss, no response to adequate standard therapy (including anti-acid medication or prokinetic drugs as appropriate), and any abnormality on physical examination.

2. Haematocrit, stool examination (including test for occult blood in the elderly) and liver and renal profiles are used as screening tests.

3. Diagnostic oesophagogastroduodenoscopy ${ }^{4}$ and biopsy of abnormal areas if any would be the next step; biopsy-based testing for $\mathrm{H}$. Pylori is done simultaneously.

4. Ultrasonography for biliary and pancreatic diseases is done when suspicion exits.

5. Further evaluation of CT scan or endoscopic retrograde cholangiopancreatography is reserved for those with abnormality on sonography.

6. Oesophageal $\mathrm{pH}^{5}$ is indicated for confirming the diagnosis of gastro-oesophageal reflux disease when suspected. Specialised tests (manometry, electrogastrography, radionuclide evaluation of gastric emptying) are confined to the research setting.

The diagnosis of functional dyspepsia requires that organic conditions with similar symptoms like peptic ulcer disease, gastro-oesophageal reflux disease, hiatal hernia, giardiasis, pancreatic and biliary diseases, be excluded by the standard investigative modalities.

\section{Treatment of Functional Dyspepsia}

- Careful inquiry into patient's medical, social and family history may uncover stress.

- Propose diagnostic evaluation that addresses the patients concerns.

- Establish a positive diagnosis of functional dyspepsia.

- Trial of drug therapy like PPI with patients complaining of dominant heartburn and epigastric pain.

- Simple dietary precautions like regular meal timings, having unhurried meals, not habitually sipping fluids during meals, avoidance of excessive spice, fatty food, and avoidance of snacks before bedtime, items rich in indigestible carbohydrates and milk, restricting intake of caffeinated and aerated beverages may all be helpful to individual patients. 
- Tobacco in any form, and immoderate alcohol consumption should be avoided.

- A suitable follow-up examination to confirm symptom response.

- Considered trial of antidepressant or referral of patients to a psychologist or a chronic pain management clinic.

\section{Drug Therapy}

\section{Anti-secretory Agents}

The efficacy of proton pump inhibitors to $\mathrm{H}_{2}$ receptors antagonist is comparable with no significant difference in reducing the symptoms.

$\mathrm{H}_{2}$ receptor antagonist - Ranitidine $150 \mathrm{mg}$ or Cimetidine $400 \mathrm{mg}$ or Famotidine $20 \mathrm{mg}$ BID daily. Proton pump inhibitors - Lansoprazole 15-30 mg, Omeprazole, esomeprazole or rabeprazole $20 \mathrm{mg}$ or pantoprazole $40 \mathrm{mg}$ daily.

Promotility agents: These agents decrease gastrooesophageal reflux, improve gastric emptying and facilitate accommodation and provide benefit to patients with functional dyspepsia having gastric emptying disorders.

Cisapride (5-10 mg BID or TID), metoclopramide (10 mg TID) can be used for short term because of their adverse effects. Domperidone (20 mg TID) can be used safely.

Anti-H. Pylori Treatment, Eradication of $\mathrm{H}$. Pylori in functional dyspepsia is unproven. Although eradicating $\mathrm{H}$. Pylori is not likely to relieve symptoms in the majority of patients with non-ulcer dyspepsia, a small proportion of $\mathrm{H}$. pylori-infected patients may benefit from eradication treatment.

According to Lr-Vedage, ${ }^{6}$ less than $15 \%$ of causes related to $\mathrm{H}$. Pylori in nonnuclear dyspepsia. Drug combinations including PPI, bismuth citrate with two antibiotics for fourteen days showed improvement in symptoms.

There is much evidence that Helicobacter pylori has been a parasite of human beings since they evolved. Organs with acid- secreting epithelia (stomach) existed in vertebrates for more than 300 million years and Helicobacter or closely related bacteria colonise the gastro-intestinal tract in many animals, including primates. ${ }^{7}$ The prevalence of Helicobacter pylori varies with age, socioeconomic status and geographic locations. Infection occurs in early childhood, in developing nations and prevalence is high in first few years of life - up to $10 \%$ per annum. The prevalence of disease in young adults in developing nations is about $80 \%$. It increases from less than $20 \%$ at 20 years of age to $50 \%$ at 50 years of age. There is 2 fold increase in prevalence in persons above 40 years old. However, the prevalence decreases in old age group due to increase in gastric atrophy in which Helicobacter pylori loses its ecological niche.

Helicobacter pylori shows substantial genetic diversity as shown by point and mosaic differences in well-conserved genes and the presence of non-conserved genes, mobile genetic elements and large scale chromosomal rearrangements. Some of these variations are markers of virulence. The enormous genotypic variation with Helicobacter pylori and the observed virulence differences among strains are consistent with the hypothesis that certain strains may not be virulent.

Exact mode of transmission of organisms is not known. The increased prevalence of Helicobacter pylori in human populations with poor hygiene, sanitation and low socioeconomic status and those living in overcrowded areas, suggests close person to person contact is an important determinant of seroprevalence of Helicobacter pylori. Direct spread from one person to another is the usual mode of spread and occurs most commonly in early life.

Helicobacter pylori is also thought to spread by faeco-oral route and this hypothesis is supported by detection of Helicobacter pylori in stool of infected persons. Helicobacter pylori is isolated from dental plaque of patients thus supporting trans-oral transmission. Helicobacter pylori, a curved rod-shaped bacterium, has been consistently associated with patients suffering from acid-peptic disease, more in ulcer disease than in non-ulcer disease. ${ }^{8}$ Due to this high association, it is now believed that Helicobacter pylori plays an important role in the aetiopathogenesis of acid-peptic disease. ${ }^{9}$

Marshall and Warren ${ }^{2}$ (1984) observed that 18 out of 22 (81\%) patients with Gastric ulcer and all the $13(100 \%)$ patients with duodenal ulcers were positive for Helicobacter pylori. ${ }^{10}$ In 59 patients with gastroduodenitis, 32 were positive for Helicobacter pylori (54.7). In patients with normal upper GI endoscopy, 8 Out of 16 (50\%) were positive for Helicobacter pylori. Elta CH, Scheiman JM, Barnett JL, Nostrant TT, Behler EM $^{11}$ in their study symptomatic improvement in 60-65\% of non-ulcer dyspepsia patients with anti-H. pylori treatment was observed. Long term symptom follow-up in both the control and infected groups gave similar results.

There was no specific symptom attributable to Helicobacter pylori infection. Helicobacter pylori is more common in males than females. Rapid urease test ${ }^{12}$ with a high sensitivity and specificity can be a useful diagnostic test for assessment of Helicobacter pylori.

Histology has been considered by some to be the gold standard for the detection of H. pylori. It, however, depends on a number of factors including the site, number, size of gastric biopsies, method of staining, and the level of experience of the examining pathologist. Serology test, however, relies on the detection of IgG antibodies specific to H. pylori.

\section{CONCLUSION}

In this study, we found that Helicobacter pylori was consistently associated with peptic ulcer disease. Hence, we recommend the eradication of bacteria in patients, positive for the bacterium, who have peptic ulcer disease and dyspepsia.

\section{REFERENCES}

[1] Perri F, Festa V, Grossi E. et al. Dyspepsia and Helicobacter pylori infection: a prospective multicenter observational study. Digestive and Liver Disease 2003;35(3):157-64.

[2] Marshall BJ, Warren JR. Unidentified curved bacilli in the stomach of patients with gastritis and peptic ulceration. The Lancet 1984;1(8390):1311-5.

[3] Jain A, Buddhiraja S, Khurana B, et al. Risk factors for duodenal ulcers in North India. Tropical Gastroenterology 1999;20(1):36-9.

[4] Fung WP, Papadimitriou JM, Matz LR. Endoscopic, histological and ultrastructural correlations in chronic gastritis. American Journal of Gastroenterology 1979;71(3):269-79. 
[5] Doenges JL. Spirochaetes in the gastric glands of Macacus rhesus and humans without definite history of related disease. Proc Soc Exp Biol Med 1938;38(4): 536-8.

[6] Vedage Lr. Psychotropic medications for the treatment of functional gastrointestinal disorders. Clinc Perspect Gastroenterol 1999:348.

[7] Dubois A, Fiala N, Weichbrod RH, et al. Seroepizootiology of Helicobacter pylori gastric infection in non-human primates housed in social environments. Journal of Clinical Microbiology 1995;33(6):1492-5.

[8] Ito S. Anatomic structure of gastric mucosa. In: Code CF. edr. Handbook of physiology, section 6, alimentary canal, Vol 2. Secretion. American Physiological Society, Washington DC: 1967:705-79.
[9] Freston JW. Helicobacter pylori- negative peptic ulcers: frequency and implications for management. Journal of Gastroenterology 2000;35(Suppl 12):29-32.

[10] Kidd M, Louw JA, Marks LN. Helicobacter pylori in Africa: observations on an 'enigma within an enigma. Journal of Gastroenterology \& Hepatology 1999;14(9):851-8.

[11] Scheiman JM, Chey WD, Behler EM, et al. One-week therapy for Helicobacter pylori. A randomized trial of two treatment regimens. Clin Gastroenterol 1996;23(3):170-3.

[12] Freedburg AS, Barron LE. The presence of spirochetes in human gastric mucosa. American Journal of Digestive Diseases 1940;7(10):443-5. 